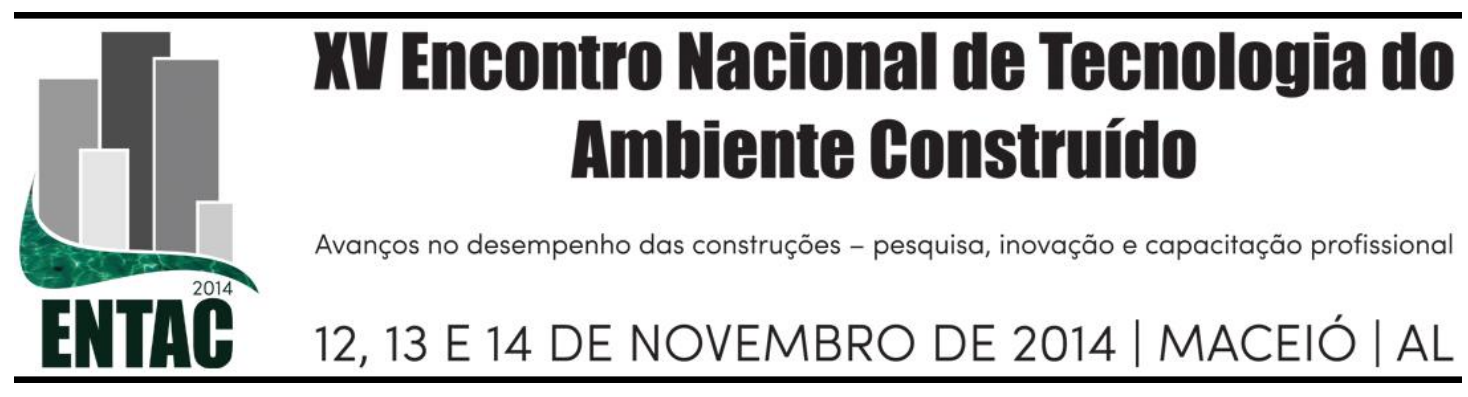

\title{
LEAN THINKING E LEAN PROJECT DELIVERY SYSTEM
}

\author{
FREITAS, Maria do Carmo (1); NASCIMENTO, Emilio L. (2); SCHEER, Sergio \\ (3); NOWACKI, Lucas (4)
}

(1) Universidade Federal do Paraná, Tel. 041.33604470, e-mail: mcf@ufpr.br (2) UFPR, Tel. 041.33604470, e-mail: emilio.ndl@gmail.com, (3) UFPR, Tel.041.33604470, e-mail: scheer@ufpr.br (4) UFPR, Tel. 041.33604470, e-mail: lucas.nowacki@gmail.com

\begin{abstract}
RESUMO
Na construção civil, a área de projeto é a responsável pelo Projeto de Desenvolvimento de Produto e enfrenta complexidade crescente necessária para a elaboração do produto edificação, atendendo soluções projetuais avançadas e gerenciando o inter-relacionamento entre agentes diferentes. A pesquisa apresentada é exploratória e faz uma análise do Lean Thinking (LT) aplicado em projetos como uma filosofia que vem sendo estudada pela academia e aplicada pelas empresas para melhorar processos, otimizar fluxos e aumentar a qualidade dos produtos. A pesquisa parte de uma pesquisa cientifica bibliográfica e tem como resultado uma proposta de checklist com aplicação do Lean Project Delivery System - LPDS - incluindo teste e validação em um escritório de Arquitetura. $\mathrm{O}$ instrumento proposto permite uma análise rápida da situação do escritório e explicita as aplicações dos conceitos de LT no desenvolvimento do produto. A expectativa é que os principais gargalos da produção do projeto arquitetônico e da própria edificação sejam explicitados, garantindo um enxugamento do tempo e do trabalho do envolvidos.
\end{abstract}

Palavras-chave: Projeto Arquitetônico, Lean Project Delivery System, Desenvolvimento de Produto, Lean Thinking.

\begin{abstract}
In construction, the project area is responsible for the design of Product Development and faces increasing complexity needed to make the product building, having advanced design solutions and managing the interrelationship between different agents. This work is exploratory and analyzes the Lean Thinking (LT) applied to projects as a philosophy that has been studied by academia and applied by companies to improve their processes, optimize flows and increase the quality of their products. The research begins on a scientific literature search and has as result a proposed checklist with application of Lean Project Delivery System - LPDS - already tested and validated in an Architecture office. The instrument allows for quick analysis of the situation of the office applications of the concepts of LT on the product development. The expectation is that the main bottlenecks in the production of architectural design and building itself are showed, wholly or partially, ensuring a downsizing of the time and work involved.
\end{abstract}

Keywords: Architectural Design, Lean Project Delivery System, Product Development, lean thinking.

\section{INTRODUÇÃO}

Na construção civil, a área de projeto é a responsável pelo Processo de Desenvolvimento de Produtos (PDP) e enfrenta complexidade crescente necessária para a elaboração do produto edificação, atendendo soluções projetuais avançadas e gerenciando o interrelacionamento entre agentes diferentes. Entretanto, ao longo dos anos, não se verifica na prática a reorganização das empresas quanto ao gerenciamento desse processo, causando resultados insatisfatórios no processo construtivo (ROMANO, 2003). 
Caracterizado como uma atividade de elevado grau de incertezas, a área de PDP trabalha manipulando e gerando volume relevante de informações que provém de diversas fontes e que possui multiplicidade de requisitos a serem atendidos considerando todas as fases do ciclo de vida do produto (AMARAL et al., 2006). É importante destacar que os autores definem o PDP como um conjunto de atividade por meio das quais se busca chegar às especificações de um produto e de seu processo de produção para que a manufatura seja capaz de produzi-lo.

No dia a dia dos escritórios de projetos, os profissionais já incorporaram conceitos de qualidade, flexibilidade, engenharia simultânea, uso de ferramentas de tecnologia da informação e o aplicam o conceito de desenvolvimento sustentável. Embora ainda existam projetistas que não consigam atender aos requisitos de qualidade nos projetos e documentos gerados. Fato que é identificado como uma das causas principais da redução de desempenho e eficiência de edificações.

$\mathrm{Na}$ literatura existem técnicas diferenciadas que são adotadas para gerenciar os problemas de projeto, tais como: reuniões coordenadas, informações via e-mail e lista de verificação. No entanto, há carência de ferramentas que resolvam os problemas relacionados aos erros de documentação. Portanto, técnicas desenvolvidas previamente em outros setores vêm sendo adaptadas. Dentre estas, o conceito de Mentalidade Enxuta (Lean thinking) considerado um novo paradigma, não só de produção, mas de negócio, envolve também desenvolvimento de produto, relação com fornecedores, estratégia de venda, gestão de pessoas, etc.

Este artigo é parte da pesquisa Tecnologia da Informação e Comunicação para Habitações de Interesse Social (TIC-HIS). Tem como resultado uma proposta de checklist com aplicação do Lean Project Delivery System - LPDS - já testado e validado em um escritório de Arquitetura, parte de uma pesquisa cientifica bibliográfica e quanto aos objetivos é exploratória. Faz uma análise do Lean Thinking aplicada a projetos como uma filosofia que vem sendo estudada pela academia e aplicada pelas empresas para melhorar seus processos, otimizar fluxos e aumentar a qualidade de seus produtos.

\section{PROCESSO DE DESENVOLVIMENTO DE PRODUTO}

Durante a etapa de Projeto, o empreendimento é formalizado e detalhado para orientar as demais atividades, portanto é a etapa onde são definidas as estratégias que guiam as decisões de projeto, os gastos de produção, a agregação de qualidade e o custo final do empreendimento. As decisões são distribuídas em diferentes fases e exercidas por diferentes agentes e esse conjunto, que extrapola as atividades da etapa de Projeto, é chamado de Processo de Projeto (FABRICIO, 2002; MELHADO, 2005).

Um produto pode possuir diferentes definições de acordo com o seu desenvolvedor, usuário e área de conhecimento, e, para a construção civil, o produto é uma edificação e o seu conjunto de bens e serviços associados (MOURA, 2005).

O PDP envolve todas as decisões e formulações que visam subsidiar a criação e a produção de um empreendimento, indo da montagem da operação imobiliária, passando pela formulação do programa de necessidades e do projeto do produto até $o$ desenvolvimento da produção, o projeto "as built" e a avaliação da satisfação dos usuários com o produto (FABRICIO, 2002). Melhado (2005) complementa que há níveis de decisão hierarquizados, dispersão de responsabilidades e baixo grau de interação entre os agentes. 
Uma iniciativa para auxiliar o PDP da construção é o uso de tecnologias e ferramentas computacionais para integrar as informações do produto e criar um modelo representativo de todas as disciplinas de projeto de forma compatibilizada e disponível para colaboração entre multiusuários (EASTMAN et al., 2008).

Entretanto não se deve concentrar esforços na tecnologia sem observar o contexto da aplicação da mesma no processo de desenvolvimento (RISCHMOLLER et al., 2006). O uso de modelos de informação pode causar excessos que levam a desperdícios e retrabalhos (SACKS et al., 2009). Exemplos do desenvolvimento enxuto da Toyota mostram que existem casos em que a adoção de tecnologia pode aumentar as dificuldades de trabalho como diminuição da transparência do processo, maior movimentação (buscas em bancos de dados) e diminuição da simplicidade, aumentando assim o número de atividades que não agregam valor ao processo (MORGAN; LIKER, 2008).

Assim, a aplicação do Pensamento Enxuto (WOMACK; JONES, 2003) em processos de desenvolvimento de produtos conduz equipes de trabalho a um processo colaborativo com potencial de conformidade e agregação de valor ao produto final, e com esforços dos participantes ao combate de desperdícios que surge em variadas formas, causando perdas, retrabalhos e aumento de custos (MORGAN; LIKER, 2008).

\subsection{Engenharia Simultânea}

O envolvimento da equipe de PDP é um requisito discutido por Fabricio (2002) por propiciar melhoria da relação entre mercado/usuário, que engloba: a) prever as demandas de mercado, seja privada ou social; b) entendimento dos requisitos dos usuários finais, realizado de forma direta com estes ou por pesquisa com usuários de empreendimentos anteriores; e c) o envolvimento antecipado de fornecedores e subempreiteiros, para garantir a qualidade ao longo do ciclo de produção e uso. Essa ativa participação da equipe permite o alinhamento das reais necessidades e expectativas dos envolvidos e permitindo a definição conjunta do empreendimento (MELHADO, 2005).

Portanto, a engenharia simultânea, ou projeto simultâneo, busca a integração dos agentes internos e externos do processo, e o desenvolvimento do projeto em equipe e de forma sistêmica. Ainda tem como objetivos a redução de custos e tempo de elaboração de projetos (MELHADO, 2005). A integração das equipes no início dos trabalhos desde o compartilhar das informações sob discussão e passíveis de mudança, que, apesar de sofrerem incertezas e alto risco, podem desenvolver senso de colaboração e de divisão de responsabilidades que é condição básica para a implementação da engenharia simultânea (TRESCASTRO, 2005).

\subsection{Integrated Project Delivery}

O Integrated Project Delivery - IPD - com tradução de Santos (2010) como Implementação Integrada de Empreendimentos, é uma iniciativa que busca formalizar o desenvolvimento integrado do processo de projeto, apoiada por órgãos reguladores americanos como o American Institute of Architects - AIA - (Instituto Americano de Arquitetos) e construtoras, projetistas e desenvolvedoras de software.

O processo de projeto que compõe o IPD é similar ao proposto pela Engenharia Simultânea, os benefícios do trabalho integrado sejam garantidos os princípios também são formalizados e as equipes são orientadas a adotá-los: a) respeito e confiança mútua; b) benefícios e recompensas compartilhadas; c) decisão e inovação colaborativas; d) envolvimento antecipado dos participantes; e) definição antecipada dos objetivos; f) planejamento intenso; g) comunicação transparente; h) adoção de tecnologia apropriada; 
e i) organização (AIA, 2007). Acrescente-se ainda que as características do relacionamento são intangíveis e possuem outros meios de motivar os participantes, como a aprendizagem organizacional, troca de tecnologias e inovação, e a construção de relacionamentos baseados em confiança, fator crucial para o sucesso do IPD (INTEGRATED PROJECT DELIVERY FOR PUBLIC AND PRIVATE OWNERS, 2010).

Cunha (2004) aponta a integração do trabalho interfuncional como solução à complexidade das questões inerentes ao desenvolvimento de um produto, ou seja, as atividades não são centradas no trabalho individual e não são voltadas a uma única área de conhecimento, são, na realidade, um conjunto de esforços de profissionais de várias áreas, num trabalho articulado e colaborativo. Isso requer reduzir ao máximo os processos burocráticos que travam o processo ágil no PDP.

\section{LEAN THINKING}

De acordo com Womack e Jones (2003), o pensamento enxuto é uma forma de especificar valor ao alinhar as ações que criam valor na melhor sequência e realiza-las sem interrupção toda vez que alguém as solicita e de forma cada vez mais eficaz.

Machado (2006) redefine o pensamento enxuto como um processo dinâmico, orientado pelo conhecimento e focado no cliente, através do qual as pessoas em uma determinada empresa eliminam desperdícios com o objetivo de criar valor.

O pensamento enxuto é definido pela geração e aperfeiçoamento de cinco princípios: valor, cadeia de valor, fluxo, puxar e perfeição, descritos nos próximos itens.

\subsection{Valor}

O valor é definido pelo cliente final e sua relevância é explicitada em um produto que atende aos requisitos do cliente com um preço, tempo e qualidade específicos. A primeira ação do pensamento enxuto é a análise e o diálogo com clientes com o objetivo de entender suas necessidades particulares (WOMACK; JONES, 2003; BAUCH, 2004).

Os processos de negócio dentro de uma empresa também são considerados uma rede de relações cliente-fornecedor e o princípio do valor se aplica para estes clientes internos. Os requisitos dos clientes, sejam internos ou externos, devem ser mantidos íntegros e não devem ser confundidos com necessidades e planos imediatos de acionistas e da alta gerência (WOMACK; JONES, 2003).

O PDP agrega valor para o cliente ao definir a qualidade final do produto e do serviço, o tempo de entrega e custos de aquisição, suporte e obsolescência. $\mathrm{O}$ valor final resultará da interação dessas definições com outras que garantem valor para os empregados e investidores do processo de desenvolvimento. Portanto, $\mathrm{O}$ valor é alcançado pela correta interpretação e tradução dos requisitos do cliente no PDP e no produto fruto deste desenvolvimento, representando o quanto o bem será estimado pelo usuário, interno e/ou externo (MACHADO, 2006).

\subsection{Cadeia de Valor}

A cadeia de valor é formada por todas as ações necessárias para produzir um produto específico, um serviço ou uma combinação de ambos, e entregá-lo ao cliente. De acordo com o potencial de geração de valor, as atividades são classificadas nas seguintes categorias (WOMACK; JONES, 2003; BAUCH, 2004), ações que: geram valor para o cliente; não geram valor para o cliente, mas são necessárias; e não geram valor para o cliente e podem ser eliminadas. 
O benefício de analisar a cadeia de valor é explicitar a geração de valor em cada etapa do desenvolvimento do produto, desde o primeiro agente do processo até o último consumidor. Empresas que fazem essa análise conseguem detectar as atividades que não geram valor e causam desperdícios e criar planos para eliminá-las ou diminuir seu impacto. (BAUCH, 2004)

\subsection{Fluxo}

As atividades que agregam valor devem fluir no processo de desenvolvimento de forma contínua e livre de desperdícios de fluxo como retrabalhos, perdas, interrupções, passos desnecessários e esperas (BAUCH, 2004; MACHADO, 2006).

O objetivo do fluxo é redefinir o modo de trabalho dos funcionários, departamentos e companhias de forma que eles possam contribuir positivamente na geração de valor, e encontrar as reais necessidades dos participantes do processo em todos os pontos ao longo da cadeia de valor, tornando-a interesse de todos. O fluxo pode ser aplicado em qualquer atividade, seguindo o mesmo procedimento (WOMACK; JONES, 2003): concentrar-se na gestão da cadeia de valor para cada produto ou serviço específico; eliminar barreiras organizacionais em nome do pensamento enxuto; realocar e redefinir o porte das ferramentas; e aplicar as práticas enxutas para que o valor flua continuamente.

\subsection{Puxar}

O princípio de puxar significa deixar o agente sucessor puxar o produto quando necessita ao invés do agente antecessor produzir em excesso, criando estoques e empurrando os produtos. Analogamente, o princípio se aplica internamente a toda cadeia de valor de uma produção, o que significa que uma operação só será realizada quando solicitada pela operação subsequente (WOMACK; JONES, 2003).

O fluxo contínuo é essencial para a realização da produção puxada, e vice-versa, resultando na diminuição do tempo total de desenvolvimento de produto, maior flexibilidade das operações e capacidade de atender os requisitos do cliente de forma exata e no momento solicitado. Para as organizações a produção puxada permite retorno acelerado do investimento, que não fica estacionado em inventários e estoques ou em atividades desnecessárias, mesmo em ambientes complexo de produção (BAUCH, 2004).

Machado (2006) afirma que o conceito de 'puxar' a produção é de difícil aplicação no PDP já que este raramente inicia-se ao ser 'puxado' por um cliente externo, pois comumente se inicia com caráter estratégico de lançar um novo produto no mercado e conseguir criar o desejo de posse por parte dos clientes. Quanto às atividades internas ao PDP, a autor afirma que características como o longo tempo de duração, simultaneidade e pouca repetição dificultam a implantação do fluxo puxado.

\subsection{Perfeição}

O último princípio é a busca da perfeição, que defende que não há fim na redução de desperdícios durante a produção, atendendo aos requisitos do cliente em melhoria contínua e simultânea dos processos. A transparência e o acesso irrestrito a dados são os mais importantes mecanismos para se alcançar a perfeição e cria um ambiente onde se torna fácil a descoberta de novas formas de criar valor (WOMACK; JONES, 2003)

\subsection{Processo de Desenvolvimento Enxuto de Produtos}

O Processo de Desenvolvimento Enxuto de Produto (PDEP) é uma abordagem para a gestão do PDP baseada nos princípios enxutos, como a busca pela maximização do valor 
agregado no produto ao cliente, diminuição dos desperdícios e busca de melhoria contínua em direção à perfeição (AMARAL et al., 2006).

$\mathrm{O}$ enfoque enxuto fornece vantagens competitivas ao aprimorar a capacidade de projetar e produzir uma maior variedade de produtos, atingindo diferentes segmentos do mercado, e permitindo obtenção de uma taxa maior de renovação de produtos, mantendo-os mais atualizados do que os da concorrência (AMARAL et al., 2006).

Fatos que motivam a proposta de um checklist rápido na fase de projetual para alerta aos membros da equipe sobre pontos importantes a observar antes de prosseguir e tornando seu PDP mais ágil e alinhado aos anseios do cliente interno e externo.

\section{MATERIAIS E MÉTODOS}

Pesquisa exploratória que utiliza os conceitos definidos por Mattar (2008), nela busca-se atingir os seguintes objetivos: familiarizar e elevar o conhecimento e compreensão de um problema de pesquisa em perspectiva; auxiliar a desenvolver a formulação mais precisa do problema de pesquisa; acumular a priori informações disponíveis relacionadas a um problema de pesquisa conclusiva a ser efetuada ou que está em andamento; ajudar no desenvolvimento ou na criação de hipóteses explicativas de fatos a serem verificados numa pesquisa causal; ajudar no desenvolvimento ou criação de questões de pesquisa relevantes para o objetivo pretendido; auxiliar na determinação de variáveis relevantes a serem consideradas num problema de pesquisa; clarificar conceitos; ajudar no delineamento do projeto final da pesquisa; verificar se pesquisas semelhantes já foram realizadas, quais os métodos utilizados e quais os resultados obtidos; e estabelecer prioridades para futuras pesquisas.

Fez-se uma análise do Lean Thinking aplicada a projetos como uma filosofia que vem sendo estudada pela academia e aplicada pelas empresas para melhorar seus processos, otimizar fluxos e aumentar a qualidade de seus produtos.

Com base nesses estudos veio a proposta de um checklist visando desenvolver um modelo de avaliação da qualidade e grau de aplicação do pensamento enxuto em escritórios de projeto. A partir da aplicação, os resultados geram uma média, que indicará uma classificação da empresa quanto ao grau de qualidade e de aplicação dos conceitos da construção enxuta em suas obras.

A classificação foi definida de AAA (de $95 \%$ a $100 \%$ da pontuação atingida, significa a busca em desenvolver a qualidade como na aplicação dos conceitos lean) até D (de $0 \%$ a $9 \%$ da pontuação, significa desalinho com a qualidade dos processos e do produto, baixo foco em melhorias, desperdícios e nenhum conhecimento da filosofia enxuta).

O estudo partiu de outro exercício anterior denominado de Rapid Lean ConstructionQuality Rating model (LCR) proposto por Hofacker et al (2008) que visava reduzir as dificuldades em mensurar as vantagens que a aplicação dos conceitos da Lean Construction trazia às empresas construtoras. $O$ modelo oferece uma avaliação categorizada, com fácil visualização e interpretação dos resultados (Figura 1).

As etapas seguintes foram retiradas da literatura e se alinham aos princípios do Lean Thinking e definida em seis categorias como segue: Atendimento das demandas, Desperdícios, Qualidade, Fluxo do processo de projeto e produção puxada, Organização, planejamento e fluxo de informações e Melhorias contínuas 


\section{Figura1 - Processo de desenvolvimento do LCR.}

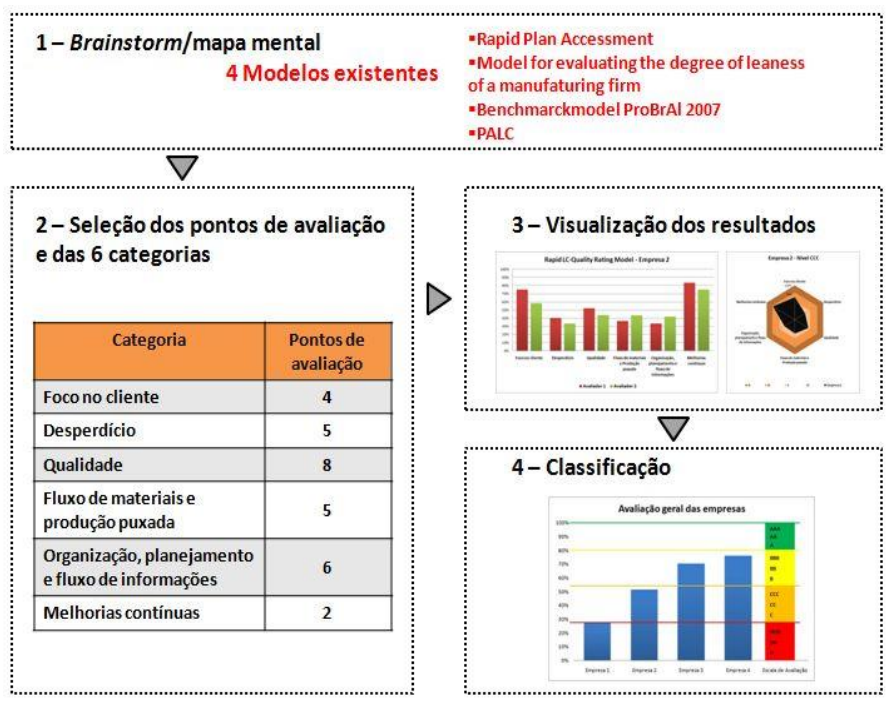

Fonte: Adaptado de Hofacker et al (2008)

Partiu-se para busca as evidencias do Lean Manangement necessárias a identificação dos pontos críticos do PDEP e definição de gradação a ser utilizada no processo de avaliação (Quadro 1). Documento completo no Apêndice A.

\section{Quadro 1 - Categorias para Lean Project Delivery System - LPDS.}

\begin{tabular}{|c|c|c|c|c|c|c|c|c|c|}
\hline Categoria & $\mathbf{N r}$ & Evidências de avaliação & \multicolumn{7}{|c|}{$\begin{array}{l}\text { Graduação } \\
0 \text { a } 6 \\
\end{array}$} \\
\hline \multirow{7}{*}{$\begin{array}{c}\text { Atendimento } \\
\text { das demandas } \\
\text { (Valor) }\end{array}$} & 1. & $\begin{array}{l}\text { O projeto é feito de maneira a buscar as necessidades } \\
\text { do usuário final. }\end{array}$ & $\mathbf{0}$ & 1 & 2 & 3 & 4 & 5 & 6 \\
\hline & 2. & Incorpora as necessidades do usuário final no projeto & $\mathbf{0}$ & 1 & 2 & 3 & 4 & 5 & 6 \\
\hline & 3. & Certeza da viabilidade econômica e temporal & $\mathbf{0}$ & 1 & 2 & 3 & 4 & 5 & 6 \\
\hline & 4. & $\begin{array}{l}\text { Busca se comunicar com os clientes internos (outros } \\
\text { projetistas) para adaptar mudanças necessárias }\end{array}$ & $\mathbf{0}$ & 1 & 2 & 3 & 4 & 5 & 6 \\
\hline & 5. & $\begin{array}{l}\text { Possui ambiente de interação entre profissionais- } \\
\text { produto-usuário }\end{array}$ & $\mathbf{0}$ & 1 & 2 & 3 & 4 & 5 & 6 \\
\hline & 6. & Nível de detalhamento dos projetos executivos & $\mathbf{0}$ & 1 & 2 & 3 & 4 & 5 & 6 \\
\hline & 7. & $\begin{array}{l}\text { Analisar se o trabalho realizado atende aos quesitos } \\
\text { do desejo, aplicabilidade e uso do usuário. }\end{array}$ & $\mathbf{0}$ & 1 & 2 & 3 & 4 & 5 & 6 \\
\hline
\end{tabular}

Fonte: Dos Autores

O conjunto de evidências total é composto de 40 questões construídas com base na escala Likert que permite ter uma visão geral de como pensam os projetistas da unidade produtiva e seus pares. Os dados podem ser visualizados individualmente ou pela média da equipe.

A classificação foi determinada de modo que as empresas que não conhecessem e/ou não aplicassem os conceitos da PDEP não pudessem atingir o nível $\mathrm{B}$ na classificação do LPDS. Apenas as empresas que aplicam a filosofia Lean Thinking em seus projetos podem atingir os níveis $\mathrm{B}$ e $\mathrm{A}$.

\section{APLICAÇÃO DO LEAN PROJECT DELIVERY SYSTEM}

Antes da aplicação do instrumento final, o mesmo foi submetido a três especialistas e posteriormente aplicado em um escritório de projeto em que os princípios do Lean Thinking (LT) já é dominado por todos a mais de dois anos. As duas aplicações trouxeram 
importantes questionamentos levando a redefinição, retirada e inclusão de outras evidências consideradas importantes pelos profissionais contatados.

O documento final foi disponibilizado na Internet, via formulário online, e tem na sua primeira página um termo de consentimento livre e esclarecido. Aborda a natureza da pesquisa e finalidade, inclusive que será utilizado em artigos científicos respeitando a confidencialidade dos nomes das empresas e respondestes.

A última etapa constou da aplicação do checklist em um escritório de arquitetura de porte médio, onde a gestora conhece dos princípios do LT. O objetivo era descobrir até quanto os conhecimentos e a cultura do Lean é repassada para sua equipe. Os resultados são apresentados na Figura 2.

Figura 2 - Avaliação de desempenho nas categorias e classificação da empresa
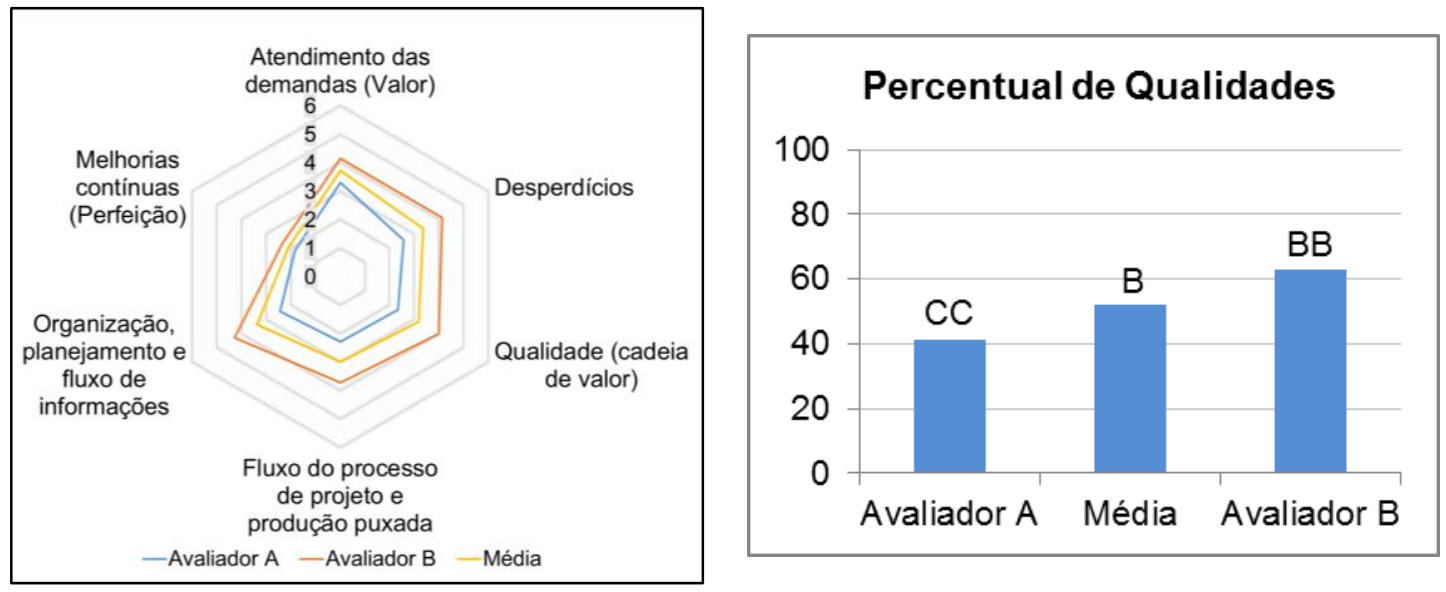

Fonte: Dos Autores

O escritório de arquitetura teve duas avaliações distintas, que resultou em uma classificação geral B, ou seja, o escritório consegue aplicar os conceitos do Lean Thinking nos seus processos. As respostas das avaliações estão presentes no Apêndice A.

As avaliações permitem mostrar que, apesar da subjetividade implícita no preenchimento do questionário, o mesmo explicita tendência similares das respostas. O Avaliador B possui uma visão mais otimista do que o avaliador A, resultando em notas maiores, entretanto os dois possuem opiniões similares no resultado geral.

Para os dois avaliadores. as práticas de "Melhorias Contínuas" são as que estão menos presentes na rotina do escritório (menores notas) e as práticas de "Organização e Fluxo de Informações" e de "Atendimento das Demandas" estão mais presentes (maiores notas).

\section{CONSIDERAÇÕES FINAIS}

A criação do Checklist foi satisfatória seguindo seu objetivo inicial, de criar um modelo para avaliar o grau de Lean que o escritório consegue colocar em prática e, consequentemente, fazendo com que o escritório tenha conhecimento de onde podem aperfeiçoar para buscar a perfeição.

Quanto a aplicação do checklist no escritório de arquitetura, foi positiva a forma com que se conseguiu avaliar o escritório e chega-se à conclusão que os conceitos do Lean Thinking estão aplicados nos processos internos.

O resultado final permitiu esclarecer o cenário do escritório estudado de acordo com os parâmetros Lean e serve de guia estratégico para definir quais categorias devem ser 
melhoradas para alcançar os objetivos e resultados da empresa e do cliente e traduzir os objetivos em ações internas à rotina dos projetistas para evoluir nas categorias escolhidas.

Espera-se, com isso, que os principais gargalos da produção do projeto arquitetônico e da própria edificação sejam explicitados, total ou parcialmente, garantindo oportunidades de combate aos desperdícios de tempo e trabalho dos envolvidos.

\section{AGRADECIMENTOS}

Ao Finep/CNPq pelos recursos financeiros da pesquisa da Rede TIC-HIS/FINEP.

\section{REFERÊNCIAS}

AMARAL, D. C.; ROZENFELD, H.; FORCELLINI, F. A.; TOLEDO, J. C.; SILVA, S.L.; ALLIPRANDINI, D. H.; SCALICE, R.K. Gestão de desenvolvimento de produtos. Editora Saraiva, 4 ed. 2006.

BAUCH, C. Lean Product Development: Making Waste Transparent. Phd Thesis. Cambridge: Massachusetts Institute of Technology, 2004.

EASTMAN, C. M.; TEICHOLZ, P.; SACKS, R. e LISTON, K. BIM Handbook: A Guide to Building Information Modeling for Owners, Managers, Designers, Engineers and Contractors. Hoboken: Wiley, 2008, 490 p.

FABRICIO, M. M. Projeto Simultâneo na construção de edifícios. Tese de Doutorado. Escola Politécnica da Universidade de São Paulo. São Paulo, 2002.

ITO, A. L. Y. Gestão de Informações no processo de projeto de Arquitetura: Estudos de Caso. Dissertação de Mestrado. Universidade Federal do Paraná. Curitiba, 2007.

MACHADO, M.C. Princípios enxutos no processo de desenvolvimento de produtos: proposta de uma metodologia de implementação. Tese de doutorado. Universidade de são Paulo. São Paulo, 2006.

MELHADO, S. B. Coordenação de projetos de edificações. Coordenador: MELHADO, S. B. São Paulo: O Nome da Rosa, 2005.

MORGAN, J. M.; LIKER, J. K. Sistema Toyota de Desenvolvimento de Produtos. Editora Bookman, 2008.

MOURA, P.M. Um Estudo sobre a Coordenação do Processo de Projeto em Empreendimentos Complexos. Dissertação de Mestrado em EngenhariaUniversidade Federal do Rio Grande do Sul, Porto Alegre, 2005

RISCHMOLLER, L.; ALARCÓN, L. F.; KOSKELA, L. Improving Value Generation in the Design Process of Industrial Projects Using CAVT. Journal of Management in Engineering, Vol.22, No. 2, 2006.

SACKS, R; KOSKELA, L.; DAVE, B. A.; OWEN, R. The Interaction of Lean and Building Information Modeling in Construction. Journal of Construction Engineering and Management, 2009.

SANTOS, E. T. Implementação Integrada de Empreendimentos (Integrated Project Delivery). Notas de Aula. Disciplina PCC5113 - Modelagem de Informações da Construção (BIM). Escola Politécnica Universidade de São Paulo, 2010.

TRESCASTRO, M. G. Diretrizes para a segmentação e seqüenciamento das atividades no processo de projeto em ambientes simultâneos na construção civil. Dissertação de Mestrado, Universidade Federal do Rio Grande do Sul, Porto Alegre, 2005.

WOMACK, J. P.; JONES, D. T. Lean thinking: banish waste and create wealth in your corporation. Free Press, 2003. 
Apêndice A - Checklist utilizado e respostas dos Avaliadores A e B.

\begin{tabular}{|c|c|c|c|c|c|c|c|c|c|c|c|}
\hline Categoria & $\mathrm{Nr}$ & Evidências de avaliação & & & Gra & & & & & \begin{tabular}{|c|} 
avaliador \\
A
\end{tabular} & $\begin{array}{c}\text { avaliador } \\
\text { B }\end{array}$ \\
\hline & 1. & $\begin{array}{l}\text { O projeto é feito de maneira a buscar as necessidades do } \\
\text { usuário final. }\end{array}$ & $\mathbf{0}$ & 1 & 2 & 3 & 4 & 5 & 6 & 5 & 6 \\
\hline & 2. & Incorpora as necessidades do usuário final no projeto & 0 & 1 & 2 & 3 & 4 & 5 & 6 & 3 & 0 \\
\hline & 3. & Certeza da viabilidade econômica e temporal & 0 & 1 & 2 & 3 & 4 & 5 & 6 & 3 & 4 \\
\hline $\begin{array}{l}\text { Atendimento } \\
\text { das demandas }\end{array}$ & 4. & $\begin{array}{l}\text { Busca se comunicar com os clientes internos (outros } \\
\text { projetistas) para adaptar mudanças necessárias }\end{array}$ & $\mathbf{0}$ & 1 & 2 & 3 & 4 & 5 & 6 & 5 & 6 \\
\hline & 5. & $\begin{array}{l}\text { Possui ambiente de interação entre profissionais-produto- } \\
\text { usuário }\end{array}$ & $\mathbf{0}$ & 1 & 2 & 3 & 4 & 5 & 6 & 2 & 5 \\
\hline & 6. & Nível de detalhamento dos projetos executivos & $\mathbf{0}$ & 1 & 2 & 3 & 4 & 5 & 6 & 3 & 3 \\
\hline & 7. & $\begin{array}{l}\text { Analisar se o trabalho realizado atende aos quesitos do desejo, } \\
\text { aplicabilidade e uso do usuário. }\end{array}$ & $\mathbf{0}$ & 1 & 2 & 3 & 4 & 5 & 6 & 2 & 5 \\
\hline & 8. & $\begin{array}{l}\text { Existe uma organização sistêmica do processo de produção de } \\
\text { projeto. }\end{array}$ & $\mathbf{0}$ & 1 & 2 & 3 & 4 & 5 & 6 & 3 & 4 \\
\hline & 9. & $\begin{array}{l}\text { Existe um acompanhamento e análise do processo de projeto } \\
\text { (foco nas perdas em todas as dimensões) }\end{array}$ & $\mathbf{0}$ & 1 & 2 & 3 & 4 & 5 & 6 & 2 & 3 \\
\hline & 10. & $\begin{array}{l}\text { Padronização do uso das etapas de projetos ou de elementos } \\
\text { conceituais. }\end{array}$ & $\mathbf{0}$ & 1 & 2 & 3 & 4 & 5 & 6 & 3 & 5 \\
\hline Desperdícios & 11. & Redução no tempo de espera entre uma etapa e outra & $\mathbf{0}$ & 1 & 2 & 3 & 4 & 5 & 6 & 2 & 4 \\
\hline & 12. & $\begin{array}{l}\text { Há plano para eliminar ou diminuir as perdas no processo de } \\
\text { projeto do produto }\end{array}$ & $\mathbf{0}$ & 1 & 2 & 3 & 4 & 5 & 6 & 2 & 3 \\
\hline & 13. & $\begin{array}{l}\text { Diversificação de softwares especialistas que requerem } \\
\text { adequações, manutenção e interoperabilidade. }\end{array}$ & $\mathbf{0}$ & 1 & 2 & 3 & 4 & 5 & 6 & 3 & 6 \\
\hline & 14. & $\begin{array}{l}\text { Realização de reuniões colaborativas entre os projetistas para a } \\
\text { busca por soluções integradas. }\end{array}$ & $\mathbf{0}$ & 1 & 2 & 3 & 4 & 5 & 6 & 3 & 4 \\
\hline & 15. & Controle de qualidade constante nos processos de projeto & $\mathbf{0}$ & 1 & 2 & 3 & 4 & 5 & 6 & 1 & 4 \\
\hline & 16. & Identificação e análise das causas dos retrabalhos & $\mathbf{0}$ & 1 & 2 & 3 & 4 & 5 & 6 & 3 & 3 \\
\hline Qualidade & 17. & Relação entre produto final e o processo de projeto & $\mathbf{0}$ & 1 & 2 & 3 & 4 & 5 & 6 & 3 & 3 \\
\hline (Cadeia de & 18. & Modularização de projeto & $\mathbf{0}$ & 1 & 2 & 3 & 4 & 5 & 6 & 1 & 5 \\
\hline valor) & 19. & Padronização de processos construtivo ou modularização & $\mathbf{0}$ & 1 & 2 & 3 & 4 & 5 & 6 & 1 & 3 \\
\hline & 20. & $\begin{array}{l}\text { Grau de automatização do processo de projeto com uso de } \\
\text { software, evitando trabalhos manuais. }\end{array}$ & $\mathbf{0}$ & 1 & 2 & 3 & 4 & 5 & 6 & 5 & 6 \\
\hline & 21 & $\begin{array}{l}\text { Existe uma forma de comunicação entre os envolvidos para } \\
\text { identificação de qual fase todos estão no processo. }\end{array}$ & $\mathbf{0}$ & 1 & 2 & 3 & 4 & 5 & 6 & 3 & 3 \\
\hline & 22. & $\begin{array}{l}\text { Possui um fluxo do projeto na área de desenvolvimento, } \\
\text { levando em conta a interação entre as partes envolvidas. }\end{array}$ & $\mathbf{0}$ & 1 & 2 & 3 & 4 & 5 & 6 & 2 & 5 \\
\hline & 23. & $\begin{array}{l}\text { Coordenação entre processo de projeto e consultorias externas } \\
\text { complementares }\end{array}$ & $\mathbf{0}$ & 1 & 2 & 3 & 4 & 5 & 6 & 2 & 3 \\
\hline $\begin{array}{l}\text { processo de } \\
\text { projeto e } \\
\text { produção }\end{array}$ & 24. & $\begin{array}{l}\text { Aplicabilidade dos conceitos BIM.- Comunicação, acesso e } \\
\text { processamento de dados, Apoio ao conhecimento e decisão } \\
\text { colaborativos e Interoperação de Sistemas. }\end{array}$ & $\mathbf{0}$ & 1 & 2 & 3 & 4 & 5 & 6 & 1 & 5 \\
\hline & 25. & Capacidade de respostas rápidas à análises de propostas & $\mathbf{0}$ & 1 & 2 & 3 & 4 & 5 & 6 & 3 & 4 \\
\hline & 26. & Capacidade de produzir estudos projetuais com rapidez & $\mathbf{0}$ & 1 & 2 & 3 & 4 & 5 & 6 & 3 & 3 \\
\hline & 27. & $\begin{array}{l}\text { Capacidade de produzir projetos executivos em curto prazo. } \\
\text { Tempo entrega do projeto ao solicitante com Baixo custo }+ \\
\text { atendimento ao munícipe. }\end{array}$ & $\mathbf{0}$ & 1 & 2 & 3 & 4 & 5 & 6 & 2 & 3 \\
\hline & 28. & $\begin{array}{l}\text { O nível de interesse da gerência sobre a análise do lean no } \\
\text { processo de projeto por demanda já aprovada. }\end{array}$ & $\mathbf{0}$ & 1 & 2 & 3 & 4 & 5 & 6 & 2 & 3 \\
\hline & 29. & Nivel de organização das atividades de gerenciamento. & $\mathbf{0}$ & 1 & 2 & 3 & 4 & 5 & 6 & 2 & 4 \\
\hline & 30. & $\begin{array}{l}\text { Grau de motivação e corresponsabilidade dos projetistas no } \\
\text { ambiente (Incentivos/motivadores) }\end{array}$ & $\mathbf{0}$ & 1 & 2 & 3 & 4 & 5 & 6 & 3 & 5 \\
\hline $\begin{array}{l}\text { Organização, } \\
\text { planejamento e }\end{array}$ & 31. & $\begin{array}{l}\text { A equipe possui a capacidade de fazer diferentes trabalhos } \\
\text { caso necessária. }\end{array}$ & $\mathbf{0}$ & 1 & 2 & 3 & 4 & 5 & 6 & 2 & 5 \\
\hline $\begin{array}{l}\text { fluxo de } \\
\text { informacões }\end{array}$ & 32. & Existência de ferramentas de interação entre a equipe. & 0 & 1 & 2 & 3 & 4 & 5 & 6 & 3 & 4 \\
\hline & 33. & $\begin{array}{l}\text { Existência de sistemas confiáveis de comunicação horizontal e } \\
\text { vertical, como e-mails, chats, etc. }\end{array}$ & 0 & 1 & 2 & 3 & 4 & 5 & 6 & 3 & 6 \\
\hline & 34. & $\begin{array}{l}\text { Sistema de gerenciamento visual no escritório (sinalização } \\
\text { clara, sinalização autoexplicativa e sistemas de controle de } \\
\text { qualidade). }\end{array}$ & 0 & 1 & 2 & 3 & 4 & 5 & 6 & 2 & 3 \\
\hline & 35. & $\begin{array}{l}\text { Existem procedimentos de Autoavaliação ao final de um } \\
\text { término de ciclo }\end{array}$ & 0 & 1 & 2 & 3 & 4 & 5 & 6 & $\mathbf{0}$ & $\mathbf{0}$ \\
\hline & 36. & $\begin{array}{l}\text { Existem reuniões frequentes com foco na aplicação de } \\
\text { melhoria no processo }\end{array}$ & 0 & 1 & 2 & 3 & 4 & 5 & 6 & 2 & 2 \\
\hline Melhorias & 37. & $\begin{array}{l}\text { Busca pela perfeição nos produtos e nos procedimentos através } \\
\text { da melhoria }\end{array}$ & 0 & 1 & 2 & 3 & 4 & 5 & 6 & 3 & 5 \\
\hline & 38. & Há atenção voltada a novas inciativas ou inovações & 0 & 1 & 2 & 3 & 4 & 5 & 6 & 3 & 4 \\
\hline & 39. & $\begin{array}{l}\text { Há um favorecimento para Educação continuada dos } \\
\text { projetistas (e.g. qualidade, cursos de especialização, Lean.). }\end{array}$ & 0 & 1 & 2 & 3 & 4 & 5 & 6 & 2 & 3 \\
\hline & 40. & $\begin{array}{l}\text { Avaliação externa. O usuário final opina e faz uma avaliação } \\
\text { sobre as facilidades e necessidades em construir as soluções do } \\
\text { projeto e se este atendeu suas necessidades. }\end{array}$ & 0 & 1 & 2 & 3 & 4 & 5 & 6 & 1 & 0 \\
\hline
\end{tabular}

